\title{
Selective proliferation of human $\Upsilon \delta$ T cells in vitro
}

CHEN SONG HuA ${ }^{1 * * *}$, AKINORI OKI $* * * * * *$, TADAo OHNO $* *$, Satoko ISHIKAWA ****, MasataKa MOCHIZUKI****, Yu FANG CHE*, Hui Ming DAI*, $\mathrm{XI}_{\mathrm{I}} \mathrm{RUI} \mathrm{GE}^{*}$

* Shanghai Institute of Cell Biology, Chinese Academy of Science, Shanghai 200031, China

** Riken Cell Bank, Koyadai, Tsukuba Science City, Japan *** Department of Gynecology, Tsukuba University, Amakubo, Tsukuba Science City, Japan **** Kyoritsu College of Pharmacy, Shibakoen, Minato-Ku, Tokyo, Japan

\section{ABSTRACT}

The effect of monoethylphosphate (MEP, commercial available or synthesized) together with IL-2 on the selective proliferation of human $\Upsilon^{\delta} \mathrm{T}$ cells in vitro from peripheral blood mononuclear cells (PBMC) of healthy donors and of cancer patients was investigated. The $\Upsilon^{\delta} \mathrm{T}$ cells were stimulated by MEP to proliferate in a dose-dependent manner. The effect of synthesized MEP was 10 times greater than that of commercial MEP. When the PBMCs of healthy donors were cultured for $25 \mathrm{~d}$ in the medium containing different concentrations of MEP, the total cell number increased about 1000-3000 fold; and the ratio of $r^{\delta} \mathrm{T}$ cells reached to $70-80 \%$. The selective expansion of $\Upsilon^{\delta} \mathrm{T}$ cells depended on the synergic action of MEP and IL-2. The bulk cultured $\Upsilon^{\delta} \mathrm{T}$ cells exhibited obvious cytotoxic activities against allogenic tumor cell lines (SQ-5, K562 and Daudi) and autologous tumor cells. The culture system described here not only offers a simple method for obtaining a large number of $\Upsilon^{\delta} \mathrm{T}$ cells which may become a new effector in the adoptive immunotherapy, but also provides a useful model for the further studies of the structure and function of $\Upsilon^{\delta} \mathrm{T}$ cells in vitro.

Key words: $\uparrow \delta T$ cells proliferation, monoethylphosphate, cytotoxicity.

1. Corresponding author 
Selective proliferation of human $\Upsilon^{\delta}$ T cells in vitro

\section{INTRODUCTION}

Although many papers have reported the diversity, development and subtype heterogeneity of $\Upsilon^{\delta} \mathrm{T}$ cells, their physiological role in the immune responses remains an important and unresolved question[i-3]. However, the accumulated experimental results provided the evidences for the specific functions of $\Upsilon^{\delta} \mathrm{T}$ cells in immunity against bacterial pathogen and viral infection[4-8], and in the anti-tumor activity in human[9]. Furthermore, the current studies suggest that $\Upsilon^{\delta} \mathrm{T}$ cells recognition may be fundamentally different from that of $\alpha \beta \mathrm{T}$ cells $[10,11]$. More importantly, the charateristics of the antigens recognized by $\Upsilon^{\delta} \mathrm{T}$ cells are more clear now[12-15]. The nonpeptide ligands for human peripheral blood $\Upsilon^{\delta} \mathrm{T}$ cells were reported recently[5, $16]$.

$\Upsilon^{\delta} \mathrm{T}$ cells comprise about $5 \%$ of the $\mathrm{CD}^{+} \mathrm{T}$ cells in human peripheral blood and lymphoid tissues[17]. Many attempts to expand these cells from the blood of healthy donors failed, because the cultures were quickly overgrown with $\alpha \beta \mathrm{T}$ cells[1].

In our present study, we confirmed the effect of MEP (monoethylphosphate, commercial or synthesized, which was reported as one of the nonpeptide ligands for human $\Upsilon^{\delta} \mathrm{T}$ cells) on the selective proliferation of $\Upsilon^{\delta} \mathrm{T}$ cells from peripheral blood mononuclear cells (PBMC) of healthy donors and cancer patients. The establishment of a culture system for the stable and optimal growth of $\Upsilon^{\delta} \mathrm{T}$ cells and the cytotoxicity of the cultured $r^{\delta}$ T cells against some autologous and allogenic tumor cells will be presented.

\section{MATERIALS AND METHODS}

\section{Cell line and culture medium}

The LAK- sensitive cell line Daudi, the NK-sensitive cell line K562 and the human lung squamous carcinoma cell line SQ-5 were provided by RIKEN Cell Bank. Recombinant human IL-2 was kindly provided by Dr. T. Hirakawa (Ajinomoto Co., Tokyo, Japan) or purchased from Shanghai Hua Xing High Bioteehnology Co., China. SQ-5, Daudi and K562 cells were maintained in MEM, RPMI-1640 and Ham's F12 supplemented with $10 \%$ FBS respectively at $37^{\circ} \mathrm{C}$ in a humidified $5 \% \mathrm{CO}_{2}$ incubator. Medium $\mathrm{RHAMa}(+)$ was developed for the induction of human LAK cells in RIKEN Cell Bank[18]. It is consisted of a mixture of RPMI-1640, Ham's F-12, and MEMa at 3:1:1 by volume, supplemented with $0.02 \mathrm{mg} / \mathrm{L}$ a-tocopherol, $0.002 \mathrm{mg} / \mathrm{L}$ sodium selenite, $0.004 \mathrm{mg} / \mathrm{L}$ linoleie acid, $0.2 \mathrm{mg} / \mathrm{ml}$ cholesterol, $500 \mathrm{mg} / \mathrm{ml}$ human albumin, $0.6 \mathrm{mg} / \mathrm{ml}$ mercaptoethanol, 0.6 $\mathrm{mg} / \mathrm{ml}$ ethanolamine, $5 \mathrm{mg} / \mathrm{ml}$ insulin, $5 \mathrm{mg} / \mathrm{ml}$ transferrin, and $66 \mathrm{mg} / \mathrm{ml}$ pyruvic acid.

\section{Monoethyl phosphate (MEP)}

The commercial MEP was purchased from Tokyo Kasei Co., Japan. It contained $42.5 \%$ pure monoethylphosphate. The synthesized MEP was produced and identified by the lab of Prof. Masataka Mochizuki (Kyoritsu College of pharmacy, Shibakoen, Minato-ku, Tokyo, Japan). The MEP was added according to the calculation of the pure MEP present in the commercial or synthesized preparations into mole solution.

\section{Preparation and culture of Mononuclear cells}

Heparinized venous peripheral blood samples were obtained from healthy human donors and 
cancer patients. Mononuclear cells (PBMC) were separated by conventional Ficoll-Hypaque density gradient centrifugation. PBMC were cultured at a concentration of $5 \times 10^{5}$ cells $/ \mathrm{ml}$ in 24 -well plates (Becton Dickinson). The culture medium was RHAMa (+) containing 5\% autoplasma, IL-2 and MEP at indicated concentrations. The cells were cultured at $37^{\circ} \mathrm{C}$ in a humidified $5 \% \mathrm{CO}_{2}$ incubator. Half of the medium was replaced with fresh medium on d 3. Subcultures were carried out every $2 \mathrm{~d}$ after $6 \mathrm{~d}$ of culture.

\section{Flow cytometric analysis of $\Upsilon^{\delta}$ and $\alpha \beta$ T cells}

At indicated times, two colour direct immunofluorescence staining was performed on PBMC (freshly isolated or cultured) with phycoerythrin-conjugated anti-TCR $\alpha / \delta$-1 MAbs (Becton Dickinson) and fluorescein isothiocyanate-conjugated anti-TCR $\alpha / \beta-1$ MAbs (Becton Dickinson). The staining procedures and the concentrations of cells and MAbs were carried out according to Becton Dickison Monoclonal Antibody Source Book. 10,000 viable cells per sample were analysed on a FACS can (Becton Dickinson) using four decade log signal amplification. All viable cells were gated by exclusion of propidium iodide $(1 \mu \mathrm{g} / \mathrm{ml})$. The data were analysed with Lysis II software (Becton Dickinson).

\section{Cell-mediated cytotoxicity assay}

The cytotoxicity of the cultured $\Upsilon^{\delta} \mathrm{T}$ cells against K562 and Daudi were measured by LDHrelease assay in $24 \mathrm{~h}$ as previously described[18]. A commercially available enzymatic test kit for LDH (Kyokuto Pharmaceutical Industries, Co., Tokyo) was used. The assays were performed automatically with a laboratory processor (Biomek 1000, Beckman Instruments, Inc., USA). The cytotoxicity to SQ-5 was measured by crystal violet staining (CV) method. Briefly, SQ-5 cells were seeded into 96-well microculture plates at a density of 100 cells/well with $100 \mu \mathrm{l}$ MEM containing $10 \% \mathrm{FBS}$, and were precultured at $37^{\circ} \mathrm{C}$ overnight. The SQ-5 cells in 6 control wells were trypsinized for counting before addition of $\Upsilon^{\delta}$ T cells. The viable taxget cells were counted with a hematocytometer, then an appropriate number of $\Upsilon^{\delta} \mathrm{T}$ cells adjusted to the desired $\mathrm{E} / \mathrm{T}$ ratio were added to each well in $100 \mathrm{ml} 5 \% \mathrm{FBS} \mathrm{RHAMa}(+)$ supplemented with $250 \mathrm{U} / \mathrm{ml} \mathrm{IL-2}$. The plates were then incubated at $37^{\circ} \mathrm{C}$ for $24 \mathrm{~h}$ in a humidified $\mathrm{CO}_{2}$ incubator. After incubation, the culture medium was discarded and the plates were washed twice with PBS. $200 \mu$ l fixing-solution ( $2 \%$ paraformaldehyde, $2 \% \mathrm{CaC1}_{2}$ ) per well was added to fix the remaining SQ- 5 cells for 1 min. Then, fixing solution was discarded and $100 \mu \mathrm{l} \mathrm{CV}$ staining solution per well was added and stained for $30 \mathrm{~min}$ at room temperature. After staining, the plates was washed with water 3 times and dried overnight in air. Then, to each well $200 \mu \mathrm{l} 70 \%$ methanol was added to extract the dye. After 1 minute extraction, the absorbance at $540 \mathrm{~nm}$ was measured.

\section{RESULTS}

\section{Selective proliferation of $\Upsilon^{\delta} T$ cells of healthy donors}

The freshly isolated PBMCs from healthy donors were cultured in the medium containning different concentrations of MEP. At different times, the cell concentrations and the percentages of $\gamma^{\delta}$ T cells and $\alpha \beta$ T cells were counted. Fig 1-3 showed some data from a typical donor KA. After $6 \mathrm{~d}$ of stimulation, the cell number (Fig 1) and the percentage of $\Upsilon^{\delta} \mathrm{T}$ cells (Fig 2A) increased in a dose-dependent manner, and the percentage of $\alpha \beta \mathrm{T}$ (Fig 2B) cells decreased correspondingly. It indicated that $0.125 \mathrm{mM}$ MEP (commercial) is sufficient to stimulate the proliferation of $\Upsilon^{\delta} \mathrm{T}$ cells (Fig 1,2). In the culture containing $1 \mathrm{~m} M \mathrm{MEP}$ (commercial), the percentage of $\Upsilon^{\delta} \mathrm{T}$ cells reached 53\% which was 23 times greater than that in the control culture containing $250 \mathrm{U} / \mathrm{ml} \mathrm{IL-2} \mathrm{but} \mathrm{without} \mathrm{MEP.} \mathrm{Additionally,} \mathrm{three} \mathrm{representatives}$ 


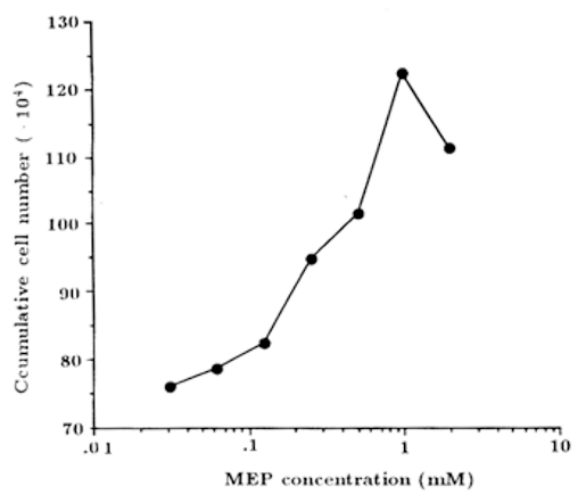

Fig 1. The dose response curve of the growth of the PBMC of the donor KA to MEP (commercial).

PBMC were cultured in $\mathrm{RHAMa}(+)$ containing $5 \%$ autoplasma, $250 \mathrm{U} / \mathrm{ml}$ IL-2 and different amounts of MEP (commercial) for $6 \mathrm{~d}$. The cell numbers were counted with hematocytometer. Values are means of duplicated wells.

MEP concentration ( $\mathrm{mM}$ )
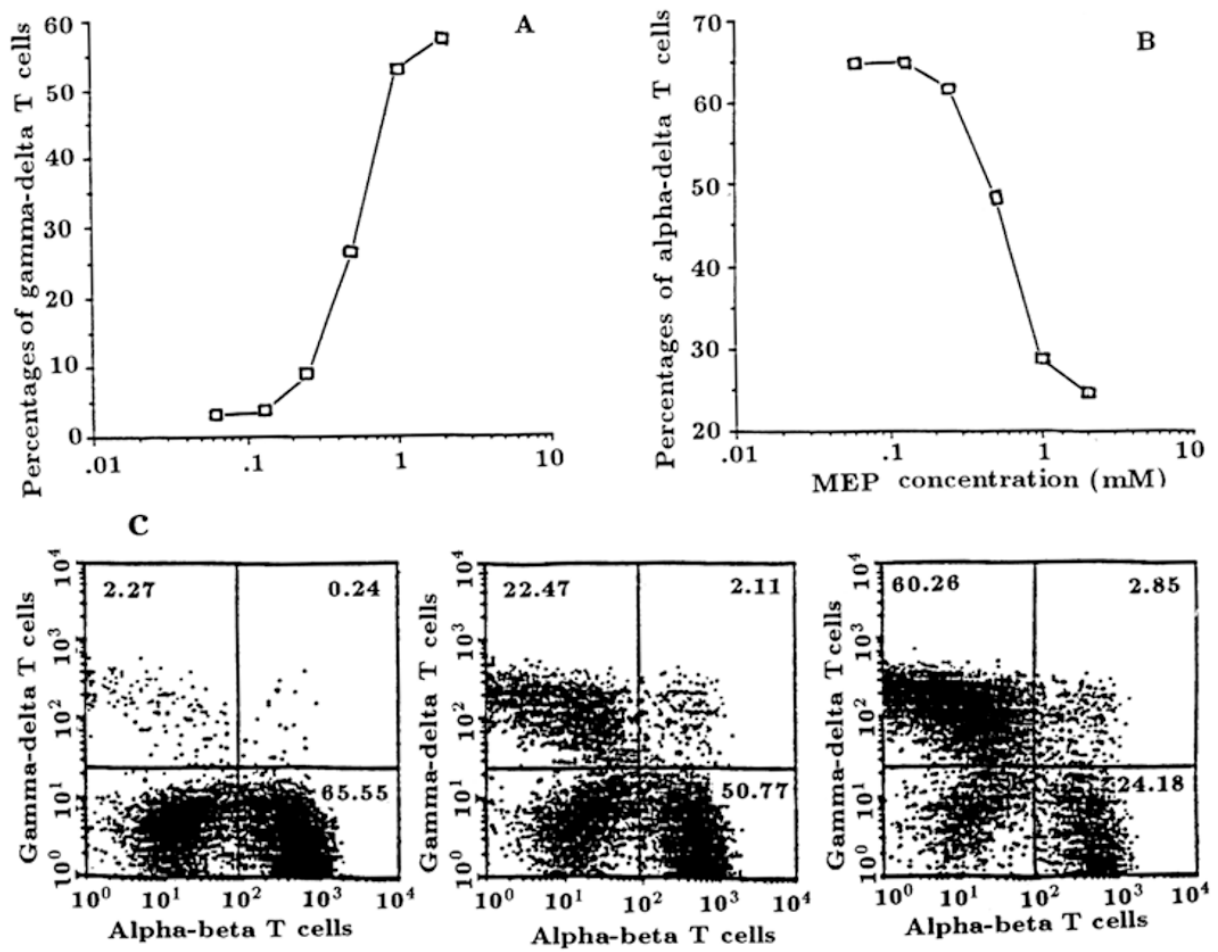

Fig 2. The dose response curve of the percentages of $\gamma^{\delta}$ and $a \beta \mathrm{T}$ cells in the cultured PBMC of the donor KA to MEP (commercial).

PBMC were cultured as indicated in Fig 1 . The percentages of the $\gamma^{\delta}$ and $\alpha \beta \mathrm{T}$ cells were measured by FACScan as described in Meterials and Methods.

(A), the percentages of $\gamma^{\delta} \mathrm{T}$ cells are means for duplicated wells.

(B), the percentages of $\alpha \beta \mathrm{T}$ cells, FACScan are means for duplicated wells.

(C), three representatives of the flow cytometric analysis in this experiment: left, control cultrue without MEP; middle, with $0.5 \mathrm{~m} M$ MEP; right, with $2 \mathrm{~m} M$ MEP. The cells from the left upper quadrants were identified as $\Upsilon^{\delta} \mathrm{T}$ cells and in the right lower quadrants as $\alpha \beta \mathrm{T}$ cells. The percentage of the cells in the quadrants are indicated. 
of the flow cytometric analysis in this experiment were shown in Fig 2C.

The time course of MEP action was briefly illustrated in Fig 3. For instance, when the PBMC were cultured in the medium containing $0.1 \mathrm{~m} M$ sythesized MEP, the percentage of $\Upsilon^{\delta} \mathrm{T}$ cells increased from 2\% in freshly isolated PBMC to 54\% on $\mathrm{d} 6$, and to $68 \%$ on $\mathrm{d} 9$ (Fig $3 \mathrm{~B}$ ), and the percentage of $\alpha \beta \mathrm{T}$ cells decreased correspondingly (Fig 3C). Furthermore, there was a correlation between the increase of the ratio of $\Upsilon^{\delta} \mathrm{T}$ cells and the increase of the cumulative cell number (Fig 3A, $3 \mathrm{~B})$.

In Tab 1, the summarized experimental results from 4 healthy donors showed that after stimulation all the percentages of $\Upsilon^{\delta} \mathrm{T}$ cells increased, and that the effect of $0.1 \mathrm{~m} M$ synthesized MEP was at least as much as that of $1 \mathrm{~m} M$ commercial MEP on raising the $\Upsilon^{\delta} \mathrm{T}$ cells percentage in $6 \mathrm{~d}$ of culture.

\section{Bulk culture of $\Upsilon^{\delta} T$ cells of healthy donors}

We found that the higher concentration of MEP were suitable for the bulk culture of $r^{\delta} \mathrm{T}$ cells. As presented in Fig 4, after $23 \mathrm{~d}$ of culture, the cumulative cell number increased from the beginning $5 \times 10^{5}$ to $5.64 \times 10^{8}$ in the culture containing $1 \mathrm{mM}$ commercial MEP, to $5.78 \times 10^{8}$ in the culture containing $0.1 \mathrm{mM}$ synthesized MEP.
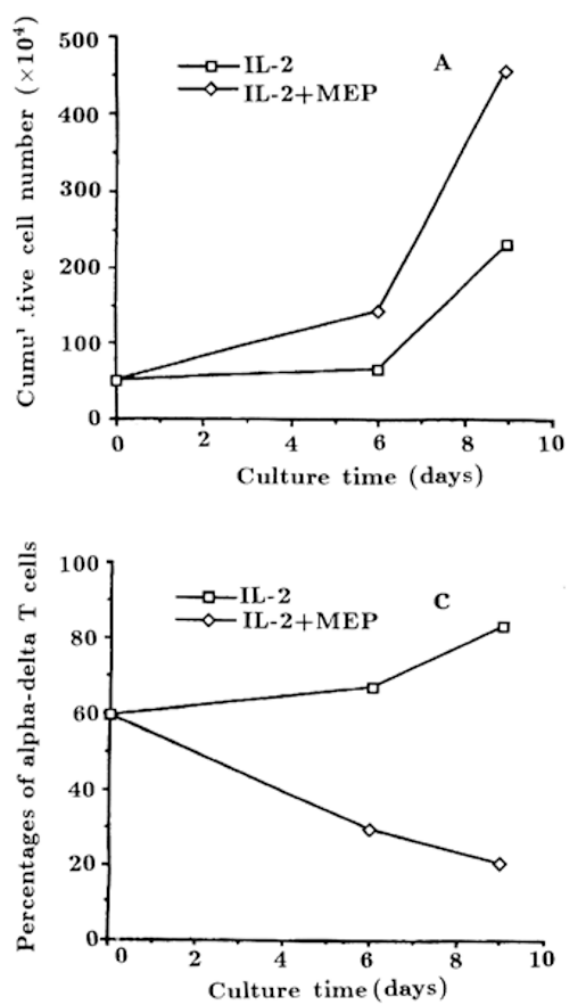

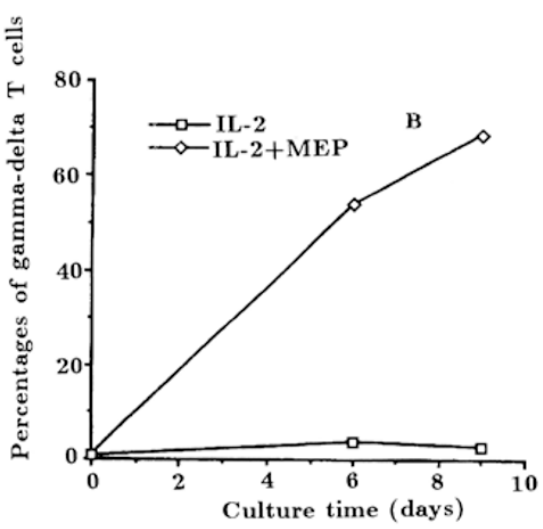

Fig 3. The effects of MEP (synthesized) on the PBMC of the donor KA.

PBMC were cultured in RHAMa(+) containing $5 \%$ autoplasma, $250 \mathrm{U} / \mathrm{ml} \mathrm{IL-2}$ and with or without $0.1 \mathrm{mM}$ MEP (synthesized). The cells numbers (A), the percentages of $\Upsilon^{\delta} \mathrm{T}$ cells (B) and $\alpha \beta \mathrm{T}$ cells $(\mathrm{C})$ were measured at 6 $d$ of culture respectively. Values are means for duplicated wells. 
Selective proliferation of human $\Upsilon^{\delta}$ T cells in vitro

Tab 1. The effects of MEP (synthesized or commercial) on the increase of the percentage of $\Upsilon^{/ \delta} \mathrm{T}$ cell of healthy donors

\begin{tabular}{lrrcc}
\hline Donor & Expt & \multicolumn{3}{c}{ The percentages of $r / \delta$ T cell } \\
\hline & & control & $\begin{array}{c}0.1 \mathrm{~m} M \text { synthesized } \\
\text { MEP }\end{array}$ & $\begin{array}{c}0.1 \mathrm{~m} M \text { commercial } \\
\text { MEP }\end{array}$ \\
\hline TK & 1 & 11.54 & 34.2 & 32.57 \\
& 2 & 12.86 & & 34.38 \\
& 3 & 7.24 & 39.79 & 54.48 \\
NM & 1 & 6.19 & 49.16 & 52.59 \\
& 2 & 7.06 & 58.12 & 24.62 \\
KA & 1 & 2.42 & 56.21 & \\
SA & 1 & 16.30 & 27.7 & \\
\hline
\end{tabular}

The PBMCs from four donors (TK, NM, KA, SA) were cultured in $\operatorname{RHAM} a(+)$ containing $5 \%$ autoplasma, $250 \mathrm{U} / \mathrm{ml} \mathrm{IL-2}$ and $0.1 \mathrm{~m} M$ synthesized MEP or $1 \mathrm{~m} M$ commercial MEP for $6 \mathrm{~d}$. The percentages of $\gamma^{\delta} \mathrm{T}$ cells were measured by FACScan. The control cultures contained $250 \mathrm{U} / \mathrm{ml} \mathrm{IL-2}$ and $5 \%$ autoplasma but without MEP.

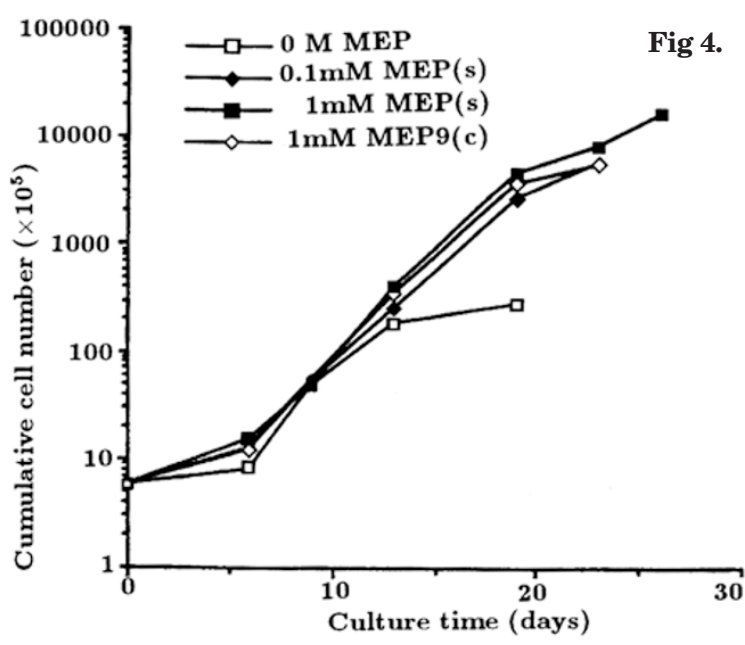

The growth curves of the PBMC of the donor $\mathrm{KA}$ in the medium containing higher concentrations of MEP.

PBMC were cultured in $\mathrm{RH}$ $\mathrm{AMa}(+)$ containing $5 \%$ autoplasma, $250 \mathrm{U} / \mathrm{ml} \mathrm{IL-2}$ and the indicated concentrations of MEP. MEP(s): synthesized MEP; MEP(c): commercial available MEP. The cell numbers were counted at indicated time respectively.

In the culture containing $1 \mathrm{~m} M$ synthesized MEP, the cell number was $8.35 \times 10^{8}$ on $\mathrm{d} 23$ and rose further to $1.68 \times 10^{9}$ on $\mathrm{d} 26$. The percentages of $\Upsilon^{\delta} \mathrm{T}$ cells in these cultures were over $70 \%$.

\section{Cytotoxic activities of $\Upsilon^{\delta}$ T cells of healthy donors against allogenic tumor cells}

The cytotoxic activities of the bulk cultured $\Upsilon^{\delta} \mathrm{T}$ cells of donor KA and donor $\mathrm{CH}$ against allogenic tumor cell lines were tested respectively. The data were shown in Fig 5. At an E/T ratio of 4, 52\% of the K562 cells and 68\% of the SQ-5 cells were killed by the $\Upsilon^{\delta}$ T cells of donor $\mathrm{CH}$ (Fig 5A). The $\Upsilon^{\delta}$ T cells from donor KA could kill $80 \%$ of the Daudi cells and $42 \%$ of the SQ-5 cells at an E/T ratio of 3 (Fig 5B). 

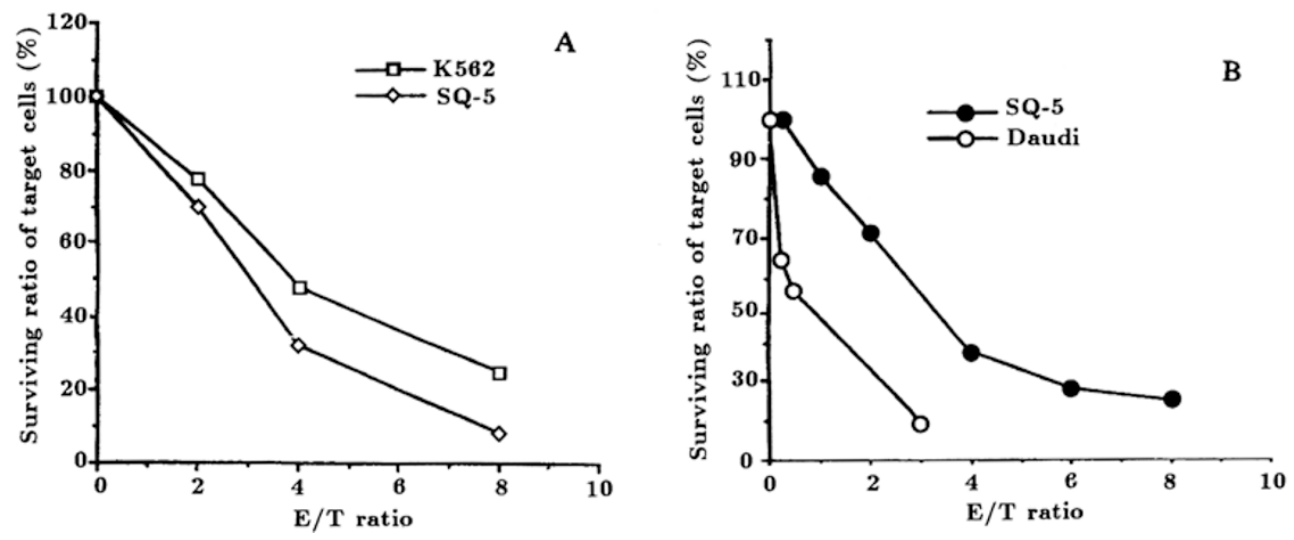

Fig 5. The cytotoxic activities of $\Upsilon^{\delta} \mathrm{T}$ cells against allogenic tumor cells. PBMC were cultured in RHAMa (+) containing $5 \%$ autoplasma, $250 \mathrm{U} / \mathrm{ml}$ IL-2 and $0.1 \mathrm{~m} M$ synthesized MEP for above 15 d. The percentages of $r^{\delta}$ T cells were above $70 \%$. The killing activities against SQ-5, K562 and Daudi cells were determined as described in Mateials and Method.

$\mathrm{A}$, the $\mathrm{PBMC}$ of donor $\mathrm{CH}$.

$\mathrm{B}$, the PBMC of donor KA. Values are means for duplicated wells.

Tab 2. The effect of MEP on the increase of the perentage of $\Upsilon^{\delta} \mathrm{T}$ cells of cancer patients

\begin{tabular}{clcc}
\hline \multirow{2}{*}{ Patient } & \multicolumn{2}{c}{ Types of cancer } & \multicolumn{2}{c}{ The percentages of $\Upsilon^{\delta}$ T cell } \\
\cline { 3 - 4 } & & & \\
& & Control culture & $1 \mathrm{~m} M$ MEP \\
\hline Kang & lung mixed adenocarcinoma & 27.86 & 93.22 \\
& squamoucarcinoma & & \\
Chou & rectal carcionoma & 5.4 & 43.68 \\
Lou & nasopharyngeal carcinoma & 4.8 & 84.68 \\
Zhu & breast cancer & 4.8 & 84.15 \\
Xin & Lung small cell cancer & 20.35 & 81.35 \\
Zhe & pancreatic carcinom & 9.37 & 57.37 \\
Liang & gastrocarcinoma & 4.76 & 74.90 \\
\hline
\end{tabular}

PBMCs from 7 cancer patients were cultured in RPMI 1640 containing $10 \%$ autoplasma, $350 \mathrm{U} / \mathrm{ml}$ IL-2 and $1 \mathrm{~m} M$ commercial MEP for about $2 \mathrm{w}$. The percentages of $\gamma^{\delta} \mathrm{T}$ cells were measured by FACScan. The control cultures contained $350 \mathrm{U} / \mathrm{ml}$ IL-2 and $10 \%$ autoplasma but no MEP.

\section{Selective expansion of $\Upsilon^{\delta} T$ cells of cancer patients}

With the same culture conditions, we succesfully induced the selective proliferation of $\Upsilon^{\delta} \mathrm{T}$ cells from PBMCs of cancer patients. As shown in Tab 2, when the PBMCs of 7 cancer patients were cultured respectively in the medium containing $1 \mathrm{~m} M$ MEP (commercial) and 350U/ml IL-2 for 10-14 d, the percentages of $\Upsilon^{\delta} \mathrm{T}$ cells rose to about $50-90 \%$ which were much higher than that in the control cultures (5\%-30\%). Moreover, the cumulative cell numbers also increased correspondingly. 


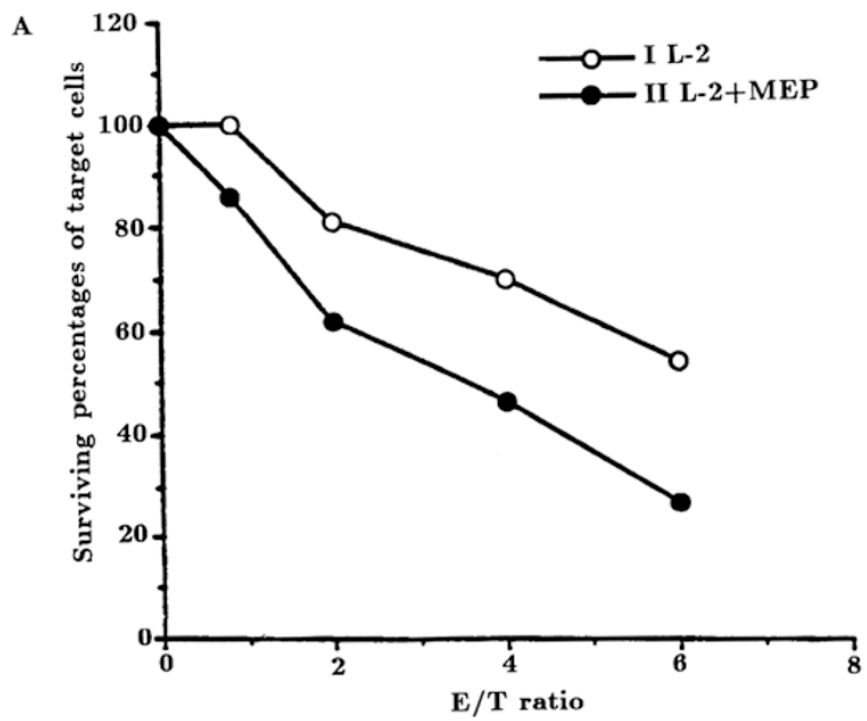

$\mathbf{B}$
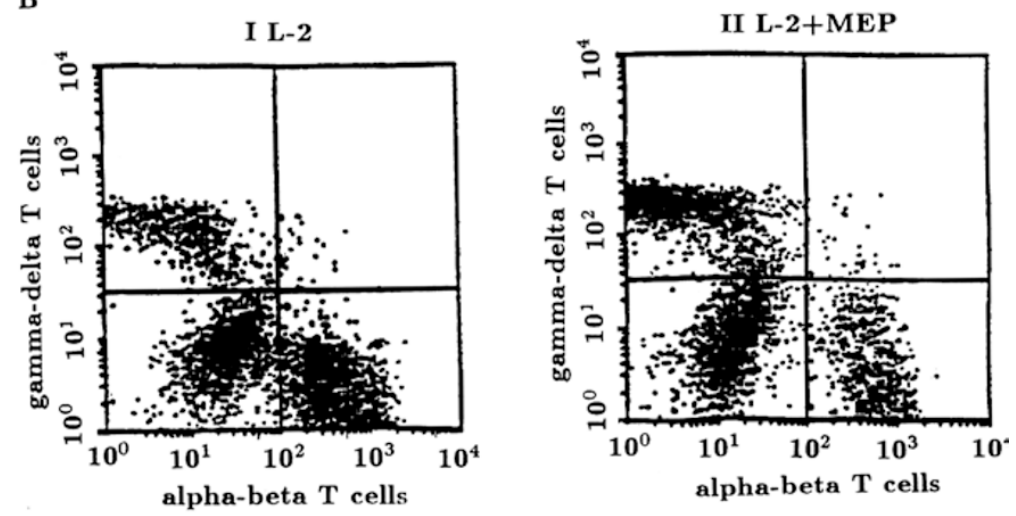

Fig 6. The cytotoxic activity of $\Upsilon^{\delta} \mathrm{T}$ cells against autologous tumor cells.

PBMCs of caner patient Opt were cultured in $\mathrm{RHAMa}(+)$ containing $5 \%$ autoplasma, $250 \mathrm{U} / \mathrm{ml} \mathrm{IL-2}$ and with (-) ) or without (-)) $1 \mathrm{mM}$ MEP (commercial) for $10 \mathrm{~d}$. A, the cytotoxic activity against autologous tumor cells (endometrium carcinoma) was tested with C.V staining method. B. the percentages of $\gamma^{\delta} \mathrm{T}$ cells and $a \beta \mathrm{T}$ cells were measured by FACScan: the cells from the left upper quadrants were identified as $\gamma^{\delta} \mathrm{T}$ cells and in the right lower quadrants as $a \beta \mathrm{T}$ cells. The percentages of the cells in the quadrants were indicated.

For example, in the patient Kang, after $2 \mathrm{w}$ culture, the percentage of $\Upsilon^{\delta} \mathrm{T}$ cells rose to $93 \%$, and the cumulative cell number increase by 100 times. 
5. Cytotoxicity of $\Upsilon^{\delta} T$ cells of the cancer patient against autologous tumor cells

We examined the cytotoxicity of the expanded $\Upsilon^{\delta} \mathrm{T}$ cells from the PBMCs of cancer patient Opt against autologous endometrium carcinoma. As shown in Fig 6 , after cultured in the medium containing $1 \mathrm{~m} M$ commercial MEP for $10 \mathrm{~d}$, the percentage of $\Upsilon^{\delta} \mathrm{T}$ cells reached $46.14 \%$, and the surviving percentage of tumor cells was $23 \%$ at $\mathrm{E} / \mathrm{T}$ ratio of 6 . However, in the control culture, the percentage of $\Upsilon^{\delta} \mathrm{T}$ cells was $14.38 \%$, and the surviving percentage of tumor cells was $57 \%$ at $\mathrm{E} / \mathrm{T}$ tatio of 6 . Therefore, there was a positive correlation between the increase of $\Upsilon^{\delta} \mathrm{T}$ cells and the cytotoxicity against autologous tumor cells.

\section{DISCUSSION}

With the combination of MEP and IL-2, we established this simple method for the selective expansion of human $\Upsilon^{\delta} \mathrm{T}$ cells in vitro. MEP alone is insufficient to induce the selective proliferaton of $\Upsilon^{\delta} \mathrm{T}$ cells and IL-2 is required for maintaining the living of $\Upsilon^{\delta} \mathrm{T}$ cells in vitro (data not shown). The lower concentrations of IL$2(200-300 \mathrm{U} / \mathrm{ml})$ are more suitable for the growth of $\Upsilon^{\delta} \mathrm{T}$ cells than the higher concentrations (500-1000 U/ml) that are usually used in LAK induction. On the other hand, even when the cultures have been induced to reach a higher percentage of $\Upsilon^{\delta} \mathrm{T}$ cells (about 80\%), it is still necessary to include MEP in the medium, otherwise the number of $\Upsilon^{\delta}$ T cells will decline.

The molecular analysis of human $\Upsilon^{\delta} \mathrm{T}$ cell clones demonstrated that the majority of $\Upsilon^{\delta} \mathrm{T}$ cells in human peripheral blood express either $\mathrm{V} \delta 2$ or $\mathrm{V} \delta 1$ gene fragement[19]. The studies with specific monoclonal antibodies showed that more than $70 \%$ of the $\Upsilon^{\delta} \mathrm{T}$ cells in human peripheral blood of most adults are $\mathrm{V} \delta 2$ subset cells[20]. The expansion of $\mathrm{V} \delta 2 \Upsilon^{\delta} \mathrm{T}$ cells in blood is thought to be the result of exposure to foreign antigens or superantigens[17]. The $\Upsilon^{\delta}$ T cells stimulated by MEP expressed $\mathrm{V}_{\Upsilon} 2 / \mathrm{V} \delta 2$ receptors[16]. According to the above information, the $\Upsilon^{\delta} \mathrm{T}$ cells expanded in our culture system are probably $\mathrm{V} \delta 2$ subset.

As for the nature of the ligands for the $\mathrm{V} \delta 2 \Upsilon^{\delta} \mathrm{T}$ cells in human peripheral blood, there were several different reports. One author reported that the ligand from mycobacterium tuberculosis (strain H37Rv) lysates is of nature of carbohydrate moeities[15]. Another two groups of workers demontrated that the ligand is homologous to the proteins of GroEL heat shock protein family[13, 14]. In another laboratory, four ligands from the same strain of mycobacterium tuberculosis were isolated and partially characterized, one of the which is a 5-triphosphorylated thymidine-containing compound[5]. Y. Tanaka and S. Sano reported that synthetic alkylphophates, particularly monoethylphosphate (MEP), can mimic small natural ligands of human $r^{\delta \mathrm{T}}$ cells [16]. They further reported that the natural antigens which are produced by mycobacteria and recognized by human $\mathrm{V}_{\Upsilon} 2 / \mathrm{V} \delta 2$-bearing $\Upsilon^{\delta}$ $\mathrm{T}$ cells are isopentenyl pyrophosphate derivatives[3]. In our experiment, the com- 
parison between two kinds of MEP (synthesized and commercial) of their effects on $r^{\delta} \mathrm{T}$ cells in 4 healthy donors (Tab 1) suggested that some modifications of the ligand in the synthesized MEP might be responsible for its increaseed efficiency in promoting $\Upsilon^{\delta}$ T cells proliferation, as compared to commercial MEP.

Another question is the mechanism by which the ligands activate $\Upsilon^{\delta} \mathrm{T}$ cells. The natural ligands were shown to exhibit all hallmarks of bacterial superantigens defined for $\alpha \beta \mathrm{T}$ cells[15]. Whether the synthetic ligands act in the same way or not is unknown. One explanation of the synergic action of MEP and IL-2 in our experiments is that $\Upsilon^{\delta} \mathrm{T}$ cells express IL-2 receptors preferentially or the affinity of their IL-2 receptors is increased under the stimulation of MEP. However, why the unique function of $\Upsilon^{\delta} \mathrm{T}$ cells has so far not been recognized? One reason is that all our present knowledge about $\mathrm{T}$ cell recognition and activation are derived from the studies on $a \beta \mathrm{T}$ cells[i]. Hence, more experiments are required to delineate the action of MEP, IL-2 on $\Upsilon^{\delta}$ T cells in detail, including the functions of the antigenpresenting cells and the other accessory cells.

In order to evaluate the functional state of the expanded $r^{\delta} \mathrm{T}$ cell in our culture system, we examined the cytotoxic activities of $\Upsilon^{\delta} \mathrm{T}$ cells against three allogenic tumor cell lines (Fig 5). Our data are consistent with the results of the other researchers[21]. Like NK cells, $\Upsilon^{\delta} \mathrm{T}$ cells in human peripheral blood mediate the non-MHC-restricted cytolytic effect against many tumor cells. We succeeded in expanding the $r^{\delta} \mathrm{T}$ cells from the PBMCs of cancer patients (Tab 2), which could obviously kill the autologous tumor cells (Fig 6) and also some allogenic tumor cells (data not shown). We intend to do more experiments to get the pattern in the cytotoxic activities of $\Upsilon^{\delta}$ T cells from different cancer patients against different allogenic tumor cells. It can be envisaged that the cultured $\Upsilon^{\delta} \mathrm{T}$ cells may be a new effector for the adoptive immunotherapy of cancer.

With regard to the responsiveness of the PBMCs from different donors, besides the different intensity described in Tab 1 and 2, we observed another kind of phenomenon, which we called $\Upsilon^{\delta}$ T cells-primed type. When the PBMCs of the donors in this type were cultured in the medium containing IL-2 (about $300 \mathrm{U} / \mathrm{ml}$ ) but without MEP, the percentage of $\Upsilon^{\delta}$ T cells also rose rapidly from below $5 \%$ to above $60 \%$ with the increase of the cumulative cell number in the culture (data not shown), suggesting that some prior activation in vivo exerted on the $r^{\delta}$ T cells. Additionally, $r^{\delta} \mathrm{T}$ cell growth was accelerated markedly in the medium containing MEP and IL-2 in the later periods of culture (data not shown). Considering the information that most $\mathrm{V} \delta 2 \Upsilon^{\delta} \mathrm{T}$ cells are positive for $\mathrm{CD} 45 \mathrm{RO}$ [1], a probable marker for immune memory cells, and that there are some contradictory results of the experiments in vivo in an attempt to clarify the way the immune system remembers past encounters with environmental pathogens[22], we think that the primed $\mathrm{V} \delta 2 \Upsilon^{\delta}$ T cells expansion in our culture system might provide a model in vitro to help the study of the mechanism of immunological memory. 


\section{REFERENCES}

[1] Haas W, Pereira P, Tonegawa S. Gamma / Delta Cells. Annu Rev Immunol 1993; 11:637-85.

[2] Viney JL, Diannda L, Roberts S J, et al. Lymphocyte proliferation in mice cogenitally deficient in T-cell receptor $a \beta^{+}$cells. Proc Natl Acad USA 1994; 91:11948-52.

[3] Tanaka Y, Morita CT, tanaka Y, Nieves E, Brenner MB. Natural and synthetic non-peptide antigens recognized by human $\Upsilon^{\delta}$ T cells. Nature 1995; 375:155-8.

[4] Ferrick DA, Schrenzel MD, Muvania T, Hsieh B, Ferlin WG, Lepper H. Differential Production of interferon- $\Upsilon$ and interleukin-4 in response to Th1 and Th2-stimulating pathogens by $\Upsilon^{\delta} \mathrm{T}$ cells in vivo. Nature 1995; 373:255-7.

[5] Constant P, Davodeau F, Peyrat MA, et al. Stimulation of human $\Upsilon^{\delta} \mathrm{T}$ cells by nonpeptidic mycobacterial ligands. Science 1994; 264:267-70.

[6] Monbaerts P, Arnoldi J, Russ F. Tonegawa S, Kaufnann SHE. Different roles of $\alpha \beta$ and $\Upsilon^{\delta} \mathrm{T}$ cells in immunity against an intracellular bacterial pathogen. Nature 1993; 365:53-6.

[7] Li W, Poberts SJ, Viney JL, et al. Immunoglobin synthesis and generalized autoimmunity in mice congenitally deficient in $\alpha \beta$ T cells. Nature 1994; 369:654-8.

[8] Sciammas R, Johnson RM, Sperling AI, et al. Unique antigen recognition by a herpesvirusspecific TCR- $\uparrow \delta$ cell. J Immunol 1994; 152:5392-7.

[9] Zocchi MR, Ferrarini M, Migone N, Casorati G. T-cell receptor Vd gene usage by tumour reactive $\Upsilon^{\delta}$ T lymphocytes infiltrating human lung cancer. Immunology 1994; 81:234-9.

[10] Schild H, Mavaddat N, Litzenberger C, et al. The nature of Major Histocompatibility Complex Recognition by $r / \delta$ T cells. Cell 1994; 76:29-37.

[11] Rock EP, Sibbald PR, Davis MM, chien YH, et al. CDR3 length in antigen-specific immune receptors. J Exp Med 1994; 179:323-8.

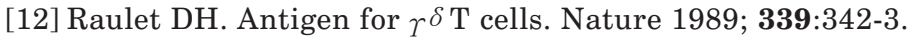

[13] Sturm E, Braaknab E, Fisch P, Vreugdenhil RJ, Sondel P, Bolhuis RLH. Human Vr $9 / \mathrm{V} \delta \mathrm{T}$ cell receptor- $\Upsilon^{\delta}$ T lymphocytes show specificity to Dandi Burkitt's lymphoma cells. J Immunol 1990; 145:3202-8.

[14] Fisch P, Malkovsky M, Kovats S, et al. Recognition by Human Vr9/V2 $\delta$ T cells of a GroEL homolog on Daudi Burkitt's lymphoma cells. Science 1990; 250:1269-73.

[15] Pfeffer K, Schoel B, Plesmila N, et al. A lectin-binding, protease-resistant mycobacterial ligand specifically activates $\mathrm{V}_{\Upsilon}^{9+}$ human T cells. J Immunol 1992; 148:575-83.

[16] Tanaka Y, Sano S, Nieves E, et al. Nonpeptide ligands for human $\Upsilon \delta$ T cells. Pro Natl Acad Sci USA 1994; 91:8175-9.

[17] Parker CM, Groh V, Band H, et al. Evidence for extrathymic changes in the T cell receptor $\Upsilon / \delta$ repertoire. J Exp Med 1990; 171:1597-1612.

[18] Kawai K, et al. Additive effects of antitumor drugs and lymphokine- activated killer cell cytotoxic activity in tumor cell killing determined by lactate- dehydrogenase- release assay. Cancer Immunol. Immunother 1992; 35:225-9.

[19] Casorati G, Libero GD, Lanzavecchia A, Migone N. Molecular analysis of human $\Upsilon / \delta^{+}$clones from thymus and peripheral blood. J Exp Med 1989; 170:1521-5.

[20] Bottino C, Tambussi G, Ferrini S, et al. Two subsets of human T lymphocytes expressing $r / \delta$ antigen receptor are identificable by monoclonal antibodies directed to two distinct molecular forms of the receptor. J Exp Med 1988; 168:491-505.

[21] Fisch P, Malkovsky M, Braakman E, et al. $r / \delta$ T cell clones and natural killer cell clones mediate distinct patterns of non-major Histocompatibility Complex-restricted cytolysis. J Exp Med 1990; 171:1567-79.

[22] Matzinger P. Memories are of this? Nature 1994; 369:605-6.

Received 10-10-1996. Revised 10-12-1996. Accepted 20-12-1996. 